\begin{tabular}{|c|c|c|}
\hline ] & $\begin{array}{l}\text { International Journal of Current Research in } \\
\text { Biosciences and Plant Biology }\end{array}$ & $=$ \\
\hline & Volume 6 •Number 1 (January-2019) • ISSN: 2349-8080 (Online) & 采. \\
\hline $\begin{array}{l}\text { EXCELLENT } \\
\text { PUBLISHERS }\end{array}$ & Journal homepage: www.ijcrbp.com & \\
\hline
\end{tabular}

\title{
Impacts of supplementary royal jelly on characteristics of post-thawed ram semen
}

\author{
Hatem ATALLA 1 *, Ahmet ESER 2, Kamber DEMİR 2, Selin YAĞCIOĞLU 2, \\ Ramazan ARICI 2, Nur ERSOY 2, Mithat EVECEN 2, Kemal AK 2, Sema BÍRLER ${ }^{2}$ \\ and Serhat PABUCCUOĞLU 2
}

\begin{abstract}
${ }^{1}$ Department of Veterinary Medicine,Faculty of Agriculture and Veterinary Medicine, An Najah National University, Nablus - PALESTINE

2 Department of Reproduction and Artificial Insemination, Faculty of Veterinary Medicine, Istanbul University, TR-34320 Avcllar, Istanbul - TURKEY

*Corresponding author; e-mail: hatematalla@najah.edu
\end{abstract}

\begin{tabular}{|c|c|}
\hline Article Info & ABSTRACT \\
\hline $\begin{array}{l}\text { Date of Acceptance: } \\
21 \text { December } 2018\end{array}$ & \multirow{6}{*}{$\begin{array}{l}\text { The motility, sperm membrane and acrosome integrity during post-thawing incubation } \\
\text { is an indication of the usability of the semen. The maintenance of higher motility of } \\
\text { sperm during post-thawing incubation simultaneously with the maintenance of intact } \\
\text { cell membrane and acrosome integrity reflects a greater likelihood of their survival in } \\
\text { the female genital tract to undergo capacitation and fertilize ova or even to be used in in } \\
\text { vitro embryo production. The aim of this study was to elucidate the protective ability of } \\
\text { royal jelly on motility, spermatozoa plasma membrane and integrity of acrosome during } \\
4 \text { hours of incubation of post-thawed ram semen in thawing media contains different } \\
\text { concentrations of RJ (o.5, } 1.0 \text { and } 2.0 \%) \text {. The post-thaw results revealed that } 0.5 \% \text { RJ } \\
\text { supplementation to incubation media significantly improved }(P<0.05) \text { total and } \\
\text { progressive motility after the second hour of incubation compared to o, } 1 \text { or } 2 \% \text { RJ } \\
\text { groups; however, a non-significant difference }(P>\text { o.o5) was obtained regarding the } \\
\text { sperm acrosome integrity across all the treatment groups. In conclusion, the structural } \\
\text { and functional parameters of sperm during -thawing can be enhanced by } \\
\text { supplementing the RJ in post-thawing media before used especially in IVF process and } \\
\text { a dose of } 0.5 \% \text { RJ provide the best post-thaw sperm quality. }\end{array}$} \\
\hline $\begin{array}{l}\text { Date of Publication: } \\
\text { o6 January } 2019\end{array}$ & \\
\hline Keywords & \\
\hline & \\
\hline Ram semen & \\
\hline Royal Jelly & \\
\hline
\end{tabular}

\section{Introduction}

Cryopreservation process including dilution, cooling, equilibration and freezing negatively affect stored semen antioxidant capacity. Due to absence or insufficiency of antioxidant mechanism of sperm cells, their lipid composition of polyunsaturated fatty acid increases the likelihood of exposure to peroxidative damage (Vernet et al., 2004). Cell plasma membrane is the first and main cellular structure affected during cryopreservation and warming processes. Its phospholipid, cholesterol and protein composition play a significant role during cooling, freezing and 
warming of sperm cells (Atalla et al., 2018). Storage of spermatozoa for long periods causes membrane weakening, because of membrane phase transition from fluid to gel state occurring in the spermatozoa plasma membrane (Graham and Foote, 1987). To protect the spermatozoa against the harmful effects of the lipid peroxidation, several researches have been made to enrich semen by adding substances such as taurine, royal jelly, catalase, trehalose, glutathione, glutathione peroxidase, cytochrome c, glutamine and hyaluronan to ram semen during cold storage (Bucak and Tekin, 2007; Moradi et al., 2013). Nevertheless, improvement in semen quality during post thawing still appears to be a challenge in sheep industry since no data available about using Royal Jelly (RJ) during the post thaw period.

The royal jelly is a white gelatinous fluid produced by the young working bees from the glands in the top of the head. This fluid is considered the main food of the queen bee and is considered to be of high nutritional value due to its special composition of sugary substances, proteins, fats, vitamins, minerals, and antioxidants which are essential for healthy bodyand healthy growth of cells (Suguru et al., 1990). More important of all, RJ's antioxidant functions have been recommended to have an exceptional effect on cells (Nagai et al., 2001).

The duration of motility, sperm membrane and acrosome integrity during post-thawing incubation is an indication of the usability of the semen. The maintenance of higher motility in sperm during post-thawing incubation simultaneously with the maintenance of intact cell membrane and acrosome integrity reflects a greater likelihood of their survival in the female genital tract to undergo capacitation and fertilize ova or even to be used in in vitro embryo production. According to our knowledge there isn't any report on enlightenment of the role of royal jelly on post-thawed ram semen parameters, especially membrane and acrosome integrity. The aim of this study was to elucidate the protective ability of RJ on spermatozoa plasma membrane and integrity of acrosome during 4 hours of incubation of post-thawed ram semen in thawing media contains different concentrations of RJ (0.5, 1.0 and 2.0\%). In addition, motility and progressive motility were evaluated.

\section{Materials and methods}

\section{Preparation of RJ}

Capsulated pure RJ was provided by Y.S. ORGANIC BEE FARMS (Illinois USA). According to manufacturer's reports, the RJ was produced from the purest beehives, which were free from chemicals or antibiotic sprays. To prepare a stock solution of RJ, the contents of two capsule (4000 $\mathrm{mg}$ ) were dissolved in 20mL TRIS (W/V) to obtain a concentration of $200 \mathrm{mg}$ of $\mathrm{RJ} / \mathrm{mL}(0.2 \mathrm{mg} / 1 \mu \mathrm{L})$ (Abd-Allah, 2012). The RJ was added to TRIS and mixed thoroughly in a shaker at $+4^{\circ} \mathrm{C}$ overnight. The prepared mixture was sterilized using a 0.22 $\mathrm{mm}$ filter and stored at $-20^{\circ} \mathrm{C}$.

\section{Frozen semen samples}

Frozen semen straws of four Kivircik rams (3 years age) were thawed by immersion in $37^{\circ} \mathrm{C}$ for $30 \mathrm{~s}$ and the semen was pooled and were mixed well in Tris buffer (0.25 M Tris, $80 \mathrm{mM}$ citric acid, $69 \mathrm{mM}$ fructose and antibiotics). Samples were divided into four equal portions in 4 test tubes. To one tube (control) only Tris-buffer was added and the remaining three tubes (experimental portions) were subjected to royal jelly treatment (0.5, 1 and $2 \%)$. All sperm suspensions were incubated at $37^{\circ} \mathrm{C}$ for various periods. Sperm motility, progressive motility, membrane and acrosome integrity analysis were performed immediately after thawing, 1, 2 and four hours after incubation with R.J.

\section{Sperm motility analysis}

Spermatological analyzes of thawed semen were evaluated by computer assisted semen analyzer (CASA 12.3 IVOS, Hamilton-Thorne Biosciences, Beverly, MA, USA). Before evaluation; of the samples, the semen analyzer was adjusted to ram sperm analysis protocol (Palacín et al., 2013). 600800 spermatozoa were evaluated for each sample and 10 different filed were evaluated (magnification) at each time. Semen incubated with different R.J rates were analyzed after 1, 2 and 4 hours postthawing. Semen samples were diluted 1:35 with TRIS buffered diluter before estimating their total and progressive motility. 


\section{Analysis of sperm membrane and acrosome integrity by using Florescent dyes}

The membrane and acrosomal-integrity stains were performed on each replicant. Membrane integrity was assessed by using a combination of propidium iodide (PI) and Carboxyfluorescein Diacetate (CFDA) fluorescent stains. This staining protocol was modified from Nuri baspinar, et al. (Başpınar et al., 2011) and Yániz, J. L., et al.(Yániz et al., 2013). Samples were diluted with normal saline (1:35). A $30 \mu \mathrm{L}$ aliquot of the diluted spermatozoa was pipetted into an eppendorf tube and stained with $10 \mu \mathrm{L}$ PI (0.5 mg/ml stock) plus $10 \mu \mathrm{L}$ CFDA (0.46 mg/ml stock). The tubes were incubated at room temperature for $5 \mathrm{~min}$ after which $5 \mu \mathrm{L}$ of Hancock solution was added to terminate sperm movement (Motility). Five $\mu \mathrm{L}$ of the stained suspension was placed on a slide under a coverslip. Two slides were prepared per sample to get a more precise estimate of the ratio of spermatozoa with intact or damaged membrane. Spermatozoa were assessed by fluorescent microscopy (Olympus BX 60) at an excitation wavelength of $485 / 20 \mathrm{~nm}$ excitation and 580-630 $\mathrm{nm}$ emission filters and a magnification of $400 \mathrm{X}$. At least 200 spermatozoa per slide were evaluated to assess sperm membrane integrity. Sperm displaying red colorization was considered as damaged membrane, while displaying green colorization was considered to be intact membrane. Sperm displaying green-red colorization was considered moribund (Fig. 1).

Acrosome integrity was assessed using Fluorescein Isothiocyanate (FITC)-labeled Lectins in combination with (PNA) peanut agglutinin (PNAFITC) (L7381 FITC-PNA, Invitrogen). A $30 \mu \mathrm{L}$ aliquot of the diluted spermatozoa was pipetted into $1.5 \mathrm{ml}$ eppendorf tube and stained with $10 \mu \mathrm{L}$ of PNA-FITC (100 $\mu \mathrm{g} / \mathrm{ml}$ stock). The tube was incubated at room temperature for 5 min after which $5 \mu \mathrm{L}$ of Hancock solution was added to terminate sperms movement. Five $\mu \mathrm{L}$ of the stained suspension was placed on a slide under a coverslip. Two slides were prepared per sample to get a more precise estimate of the acrosome integrity. Spermatozoa were assessed by fluorescent microscopy (Olympus BX 60) at an excitation wavelength of $450-490 \mathrm{~nm}$ excitation and $515 \mathrm{~nm}$ emission filters and a magnification of 400X. At least 200 spermatozoa per slide were evaluated. Spermatozoa displaying bright green or patchy green fluorescence were considered as acrosome non-intact or damaged, whereas cells which did not stain green fluorescence in acrosome cap were regarded as acrosome intact (Fig. 2).

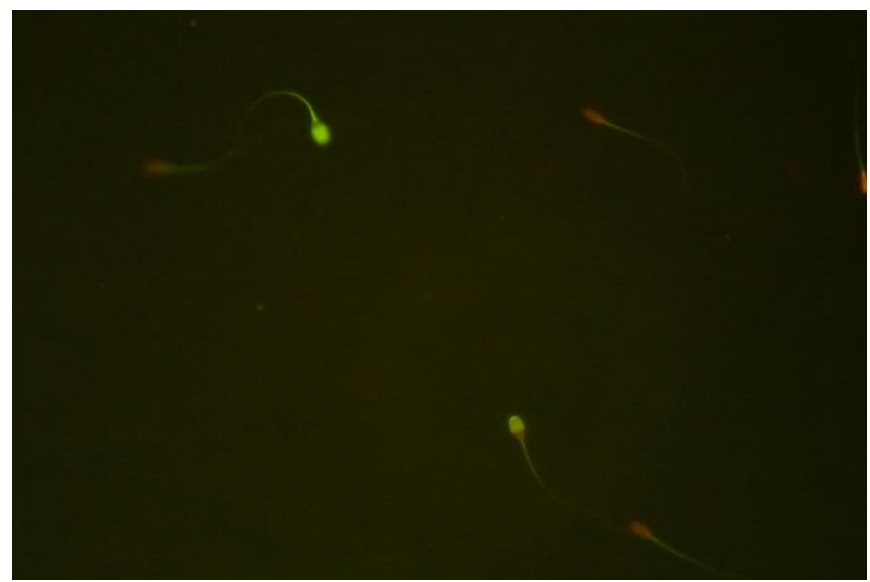

Fig. 1: membrane staining with PI-CFDA fluorescent stains.

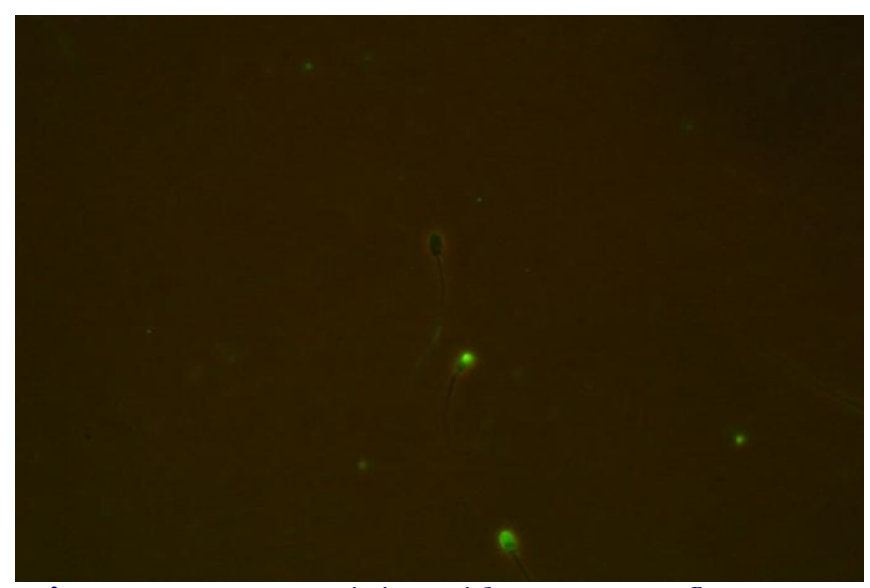

Fig. 2: Acrosome staining with PNA-FITC fluorescent stains.

\section{Statistical analysis}

One-way variance analysis was used to evaluate the significance levels between the parameters studied. A $p$ value of 0.05 was selected as a criterion for statistically significant differences.

\section{Results}

The effect of RJ supplementation in extender on total motility, progressive motility, sperm plasma membrane and acrosomal integrity has been presented in Tables 1 to 4 . The post-thaw results 
revealed that $0.5 \%$ RJ supplemented significantly improved $(P<0.05)$ total and progressive motility after the second hour of incubation compared to 0 , 1 or $2 \%$ RJ groups; nonetheless, a non-significant difference in these parameters was observed during the first hour incubation among the control group and $0.5 \%$ RJ supplemented group (Table 1 and Table 2).

Table 1. Motility of Ram spermatozoa thawed and held in Tris-royal jelly extender (o.0-2.0\%) over $4 \mathrm{~h}$ incubation period $(\bar{x} \pm \mathrm{SE})$.

\begin{tabular}{|c|c|c|c|c|}
\hline \multirow[b]{2}{*}{$\begin{array}{l}\text { Incubation } \\
\text { period }\end{array}$} & \multicolumn{4}{|c|}{ Concentrations of royal jelly } \\
\hline & $\begin{array}{l}\text { Group } 1 \text { (control) } \\
\text { (o\% RJ) }\end{array}$ & Group 2 (0.5\% RJ) & Group 3 (1.0\% RJ) & Group 4 (2.0\% RJ) \\
\hline 0 & $59 \pm 0.21^{\text {aA }}$ & $59 \pm 0.21^{\mathrm{aA}}$ & $59 \pm 0.21^{\mathrm{aA}}$ & $59 \pm 0.21^{\mathrm{aA}}$ \\
\hline $1^{\text {st }}$ hour & $53 \pm 0.16^{\mathrm{aA}}$ & $53 \pm 0.16^{\mathrm{aA}}$ & $42 \pm 0.25^{\mathrm{bB}}$ & $38 \pm 0.23^{\mathrm{bB}}$ \\
\hline $2^{\text {nd }}$ hour & $44 \pm 0.15^{\mathrm{bB}}$ & $51 \pm 0.15^{\mathrm{aA}}$ & $25 \pm 0.11^{\mathrm{cC}}$ & $23 \pm 0.14^{\mathrm{cB}}$ \\
\hline $4^{\text {th }}$ hour & $24 \pm 0.13^{\mathrm{bC}}$ & $31 \pm 0.2^{\mathrm{aB}}$ & $11 \pm 0.14^{\mathrm{cD}}$ & $6 \pm 0.1^{\mathrm{dC}}$ \\
\hline
\end{tabular}

Each value represents $\overline{\mathrm{x}} \pm \mathrm{SE}$ of fifteen observations of double thawed straws. Values with the different superscript (a$\mathrm{b}-\mathrm{c}-\mathrm{d})$ in the same row or $(\mathrm{A}-\mathrm{B}-\mathrm{C}-\mathrm{D})$ in the same column were significantly different at $p<0.05$.

Table 2. Progressive Motility of Ram spermatozoa thawed and held in Tris-royal jelly extender (o.o-2.0\%) over $4 \mathrm{~h}$ incubation period $(\bar{x} \pm \mathrm{SE})$.

\begin{tabular}{lllll}
\hline $\begin{array}{l}\text { Incubation } \\
\text { period }\end{array}$ & $\begin{array}{l}\text { Concentrations of royal jelly } \\
\text { Group 1 (control) } \\
\text { (o\% RJ) }\end{array}$ & Group 2 (o.5\% RJ) & Group 3 (1.0\% RJ) & Group 4 (2.0\% RJ) \\
\hline $\mathrm{O}$ & $35 \pm 0.21^{\mathrm{aA}}$ & $35 \pm 0.21^{\mathrm{aA}}$ & $35 \pm 0.21^{\mathrm{aA}}$ & $35^{\mathrm{A}} \mathrm{O} .21^{\mathrm{aA}}$ \\
$1^{\text {st }}$ hour & $36 \pm 0.22^{\mathrm{aA}}$ & $38 \pm 0.25^{\mathrm{aA}}$ & $20 \pm 0.17^{\mathrm{bB}}$ & $21 \pm 0.19^{\mathrm{bB}}$ \\
$2^{\text {nd }}$ hour & $22 \pm 0.15^{\mathrm{bB}}$ & $31 \pm 0.2^{\mathrm{aA}}$ & $17 \pm 0.11^{\mathrm{bB}}$ & $15 \pm 0.15^{\mathrm{bB}}$ \\
$4^{\text {th }}$ hour & $16 \pm 0.11^{\mathrm{bC}}$ & $22 \pm 0.18^{\mathrm{aB}}$ & $2 \pm 0.1^{\mathrm{cC}}$ & $1 \pm 0.1^{\mathrm{cC}}$ \\
\hline Each value represents $\overline{\mathrm{X}} \pm \mathrm{SE}$ of fifteen observations of double thawed straws. Values with the different superscript (a- \\
b-c) in the same row or (A-B-C) in the same column were significantly different at $p<0.05$.
\end{tabular}

Table 3. Membrane integrity (stained with CFDA:PI) of Ram spermatozoa thawed and held in Tris-royal jelly extender $(0.0-2.0 \%)$ over $4 \mathrm{~h}$ incubation period $(\bar{x} \pm \mathrm{SE})$.

\begin{tabular}{|c|c|c|c|c|}
\hline \multirow{2}{*}{$\begin{array}{l}\text { Incubation } \\
\text { period }\end{array}$} & \multicolumn{4}{|c|}{ Concentrations of royal jelly } \\
\hline & $\begin{array}{l}\text { Group } 1 \text { (control) } \\
\text { (o\% RJ) }\end{array}$ & Group 2 (0.5\% RJ) & Group 3 (1.0\% RJ) & Group 4 (2.0\% RJ) \\
\hline $\mathbf{0}$ & $38 \pm 0.17^{\mathrm{aA}}$ & $38 \pm 0.17^{\mathrm{aA}}$ & $38 \pm 0.17^{\mathrm{aA}}$ & $38 \pm 0.17^{\mathrm{aA}}$ \\
\hline $1^{\text {st }}$ hour & $25 \pm 0.19^{\mathrm{bB}}$ & $37 \pm 0.20^{\mathrm{aA}}$ & $38 \pm 0.21^{\mathrm{aA}}$ & $32 \pm 0.19^{\mathrm{aA}}$ \\
\hline $2^{\text {nd }}$ hour & $22 \pm 0.17^{\mathrm{bB}}$ & $33 \pm 0.19^{\mathrm{aA}}$ & $31 \pm 0.19^{\mathrm{aA}}$ & $30 \pm 0.20^{\mathrm{aA}}$ \\
\hline $4^{\text {th }}$ hour & $13 \pm 0.11^{b C}$ & $35 \pm 0.15^{\mathrm{aA}}$ & $28 \pm 0.14^{\mathrm{bA}}$ & $30 \pm 0.21^{\mathrm{bA}}$ \\
\hline
\end{tabular}

Each value represents $\overline{\mathrm{x}} \pm \mathrm{SE}$ of fifteen observations of double thawed straws. Values with the different superscript (a-

b) in the same row or $(\mathrm{A}-\mathrm{B}-\mathrm{C})$ in the same column were significantly different at $p<0.05$.

Table 4. Acrosome integrity (stained with PNA: FITC) of Ram spermatozoa thawed and held in Tris-royal jelly extender $(0.0-2.0 \%)$ over $4 \mathrm{~h}$ incubation period $(\bar{x} \pm \mathrm{SE})$.

\begin{tabular}{|c|c|c|c|c|}
\hline \multirow[b]{2}{*}{$\begin{array}{l}\text { Incubation } \\
\text { period }\end{array}$} & \multicolumn{4}{|c|}{ Concentrations of royal jelly } \\
\hline & $\begin{array}{l}\text { Group } 1 \text { (control) } \\
\text { (o\% RJ) }\end{array}$ & Group 2 (0.5\% RJ) & Group 3 (1.0\% RJ) & Group 4 (2.0\% RJ) \\
\hline $\mathbf{0}$ & $36 \pm 0.16^{\mathrm{aA}}$ & $36 \pm 0.16^{\mathrm{aA}}$ & $36 \pm 0.16^{\mathrm{aA}}$ & $36 \pm 0.16^{\mathrm{aA}}$ \\
\hline $1^{\text {st }}$ hour & $35 \pm 0.15^{\mathrm{bA}}$ & $38 \pm 0.18^{\mathrm{bA}}$ & $47 \pm 0.19^{\mathrm{aA}}$ & $41 \pm 0.14^{\mathrm{bA}}$ \\
\hline $2^{\text {nd }}$ hour & $38 \pm 0.18^{\mathrm{bA}}$ & $41 \pm 0.2^{\mathrm{bA}}$ & $44 \pm 0.16^{\mathrm{aA}}$ & $45 \pm 0.17^{\mathrm{bA}}$ \\
\hline $4^{\text {th }}$ hour & $34 \pm 0.14^{\mathrm{aA}}$ & $40 \pm 0.2^{\mathrm{aA}}$ & $38 \pm 0.18^{\mathrm{aA}}$ & $40 \pm 0.15^{\mathrm{aA}}$ \\
\hline
\end{tabular}

Each value represents $\overline{\mathrm{x}} \pm \mathrm{SE}$ of fifteen observations of double thawed straws. Values with the different superscript (a-

b) in the same row or (A-B) in the same column were significantly different at $p<0.05$.

Higher percentage of sperm with intact membrane were observed in $0.5 \% \mathrm{RJ}$ compared to 1 and $2 \% \mathrm{RJ}$ supplemented groups; whereas, similar proportion of sperm with intact membrane were present in 1 
and $2 \%$ RJ supplemented groups. All RJ supplemented groups were significantly improved sperm membrane intactness compared to control group at the end of incubation period $(P<0.05)$.

In addition, the sperm acrosome integrity was similar $(P>0.05)$ across all the treatment groups, nevertheless the lower acrosome integrity rates were observed with the control group.

\section{Discussion}

The In recent years different semen additives, especially antioxidants, have been used to combat reactive oxygen species (ROS) damage which ruptures the membrane integrity in ram semen and reduces motility. In these studies, Tris-citricacid-fructose-glycerol-based or milky diluents are generally used, good results are obtained from some of them and some results are inadequate.(Graham and Foote, 1987; Maxwell and Stojanov, 1996).

In addition, to increase the freezing success of the ram's sperm, antioxidants are added in order to prevent the damage caused by reactive oxygen species (ROS) which disrupts sperm membrane integrity. Particularly, the results obtained from the studies involving diluent additives like thiol compounds, cysteine and trehalose(UÇ, 2015).

An improvement in post-thaw sperm quality and integrity by RJ protection has been clarified after repeated observations. Similarly, previous studies have shown that RJ (o.1\%) supplementation improved the sperm viability, plasma membrane and acrosome integrity of buffalo sperm (Shahzad et al., 2016). Additionally, a significant protective effect of RJ on ram sperm membrane functionality was obtained at lower concentrations (0.5 and 1\%) during liquid storage and serves as an antioxidant source (Moradi et al., 2013).

The sperm motility is one the most important parameter of sperm quality evaluation that reflects the sperm post-thaw ability to fertilize oocytes in both in-vivo and in-vitro conditions. The current results revealed that a low concentration of $\mathrm{RJ}$ (0.5\%) supplementation in thawing media significantly $(p<0.5)$ enhanced the sperm motility, progressive motility and membrane integrity but doesn't improved acrosome intactness at the end of 4 hours incubation. This significant increase in post-thaw sperm motility and membrane integrity could be related to the effect of antioxidant potency of RJ when compared to RJ free incubation medium. On the other hand, spermatozoa incubated in higher RJ concentration (1.0 and 2.0\%) showed significantly lower motility rates than the control and low RJ concentration groups. Higher concentrations of RJ may negatively alter the osmolarity or PH of incubation media which caused decreased motility rates.

It was noticed that $\mathrm{RJ}$ works more safely in lower concentrations of $\mathrm{RJ}(0.5 \%)$ and it provide a great opportunity to maintain of sperm quality during thawing and post-thawing periods. In contrast, high concentration ( 1 and $2 \%$ ) of RJ did not provide any effect on sperm quality during postthawing incubation period The negative response with higher concentration of RJ in the present study is concomitant with earlier studies where high concentrations of RJ (Abd-Allah, 2012; Moradi et al., 2013) or other antioxidants like taurine, BHT, cysteine, glutathione, ascorbic acid or glycine (Ijaz et al., 2009; Khalili et al., 2010; Szcześniak-Fabiańczyk et al., 2003) have been used to determine their dose effect on sperm quality during cryopreservation and thawing.

\section{Conclusion}

In conclusion, the structural and functional parameters of sperm during -thawing can be enhanced by supplementing the RJ in postthawing media before used especially in IVF process and a dose of $0.5 \%$ RJ provide the best post-thaw sperm quality.

\section{Conflict of interest statement}

Authors declare that they have no conflict of interest.

\section{References}

Abd-Allah, S.M., 2012. Effect of royal jelly on viability and in vitro maturation of Egyptian sheep oocytes in serum supplemented medium. Br J. Pharmacol. Toxicol. 3, 29-32.

Atalla, H., Demir, K., Arici, R., Yagcioglu, S., Eser, A., Ersoy, N., Coskun, N., Alzuheir, I., Evecen, M., Birler, S., 2018. Effect of cholesterol loaded methyl-beta-cyclodextrin on ovine oocytes 
during chilling and vitrification. Rev. Med. Vet. 169, 241-246.

Başpınar, N., Çoyan, K., Bucak, M.N., Tuncer, P.B., 2011. Effects of dithioerythritol on ram semen after the freeze-thawing process. Cryobiology. 63 (3), 152-156.

Bucak, M.N., Tekin, N., 2007. Protective effect of taurine, glutathione and trehalose on the liquid storage of ram semen. Small Rumin. Res. 73 (13), 103-108.

Graham, J., Foote, R., 1987. Effect of several lipids, fatty acyl chain length, and degree of unsaturation on the motility of bull spermatozoa after cold shock and freezing. Cryobiology. 24 (1), 42-52.

Ijaz, A., Hussain, A., Aleem, M., Yousaf, M., Rehman, H., 2009. Butylated hydroxytoluene inclusion in semen extender improves the postthawed semen quality of Nili-Ravi buffalo (Bubalus bubalis). Theriogenology. 71 (8), 1326-1329.

Khalili, B., Jafaroghli, M., Farshad, A., PareshKhiavi, M., 2010. 43 the effects of different concentrations of Glycine and cysteine on the freezability of Moghani ram spermatozoa. Asian-Australas J. Anim. Sci. 23 (3), 318.

Maxwell, W., Stojanov, T., 1996. Liquid storage of ram semen in the absence or presence of some antioxidants. Reprod. Fertil. Dev. 8 (6), 10131020.

Moradi, A., Malekinejad, H., Farrokhi-Ardabili, F., Bernousi, I., 2013. Royal Jelly improves the sperm parameters of ram semen during liquid storage and serves as an antioxidant source. Small Rumin. Res. 113 (2-3), 346-352.
Nagai, T., Sakai, M., Inoue, R., Inoue, H., Suzuki, N., 2001. Antioxidative activities of some commercially honeys, royal jelly, and propolis. Food Chem. 75 (2), 237-240.

Palacín, I., Vicente-Fiel, S., Santolaria, P., Yániz, J., 2013. Standardization of CASA sperm motility assessment in the ram. Small Rumin. Res. 112 (1-3), 128-135.

Shahzad, Q., Mehmood, M.U., Khan, H., ul Husna, A., Qadeer, S., Azam, A., Naseer, Z., Ahmad, E., Safdar, M., Ahmad, M., 2016. Royal jelly supplementation in semen extender enhances post-thaw quality and fertility of Nili-Ravi buffalo bull sperm. Anim. Reprod. Sci. 167, 83-88.

Suguru, F., Jiro, I., Mineko, F., Tomoko, Y., Takuji, K., Kumpei, K., 1990. A potent antibacterial protein in royal jelly. J. Biol. Chem. 265, 1133311337.

Szcześniak-Fabiańczyk, B., Bochenek, M., Smorag, Z., Ryszka, F., 2003. Effect of antioxidants added to boar semen extender on the semen survival time and sperm chromatin structure. Reprod. Biol. 3 (1), 81-87.

UÇ, A., 2015. The effects of L-ergothioneine, Nacetylcystein and cystein on freezing of ram semen. Kafkas Univ. Vet. Fak. Derg. 21(1), 81-86.

Vernet, P., Aitken, R., Drevet, J., 2004. Antioxidant strategies in the epididymis. Mol. Cell Endocrinol. 216 (1-2), 31-39.

Yániz, J., Palacín, I., Vicente-Fiel, S., Gosalvez, J., López-Fernández, C., Santolaria, P., 2013. Comparison of membrane-permeant fluorescent probes for sperm viability assessment in the ram. Reprod. Domest. Anim. 48 (4), 598-603.

\section{How to cite this article:}

Atalla, H., Eser, A., Demir, K., Yağcioğlu, S., Arici, R., Ersoy, N., Evecen, M., Ak, K., Birler, S., Pabuccuoğlu, S., 2019. Impacts of supplementary royal jelly on characteristics of post-thawed ram semen. Int. J. Curr. Res. Biosci. Plant Biol. 6(1), 6-11. doi: https://doi.org/10.20546/ijcrbp.2019.601.002 